\title{
Facile Synthesis of the Dicyanophosphide Anion via Electrochemical Activation of White Phosphorus: An Avenue to Organophosphorus Compounds
}

\author{
Yanbo Mei, Zeen Yan, Liu Leo Liu* \\ Department of Chemistry and Shenzhen Grubbs Institute, Southern University of Science and Technology, Shenzhen 518055, \\ China
}

Supporting Information Placeholder

\begin{abstract}
Organophosphorus compounds (OPCs) have gained tremendous interest in the past decades due to their wide applications ranging from synthetic chemistry to materials and biological sciences. We describe herein a practical and versatile approach for the transformation of white phosphorus $\left(\mathrm{P}_{4}\right)$ into useful OPCs with high $\mathrm{P}$ atom economy via a key bridging anion $\left[\mathrm{P}(\mathrm{CN})_{2}\right]^{-}$. This anion can be prepared on a gram scale directly from $\mathrm{P}_{4}$ through an electrochemical process. A variety of OPCs involving phosphinidenes, cyclophosphanes and phospholides have been made readily accessible from $\mathrm{P}_{4}$ in a two-step manner. Our approach has a significant impact on the future preparation of OPCs in laboratory and industrial settings.
\end{abstract}

Organophosphorus compounds (OPCs) are widely used as herbicides, flame-retardants, ligands, pharmaceuticals, detergents, and photo-initiators. ${ }^{1}$ Currently, their industrial syntheses demand two phosphorus transfer reagents, namely phosphorus trichloride $\left(\mathrm{PCl}_{3}\right)$ and phosphine gas $\left(\mathrm{PH}_{3}\right) . \mathrm{PCl}_{3}$ is a highly corrosive liquid, which is produced by oxidation of white phosphorus $\left(\mathrm{P}_{4}\right)$ with toxic chlorine gas. The preparation of OPCs via $\mathrm{PCl}_{3}$ involves stepwise displacement of the chloride atoms, and thus inherently has low selectivity and efficiency while concurrently generating chlorine containing waste. ${ }^{2}$ Catalytic transformation of $\mathrm{PH}_{3}$ into OPCs is less preferred as $\mathrm{PH}_{3}$ is an extremely toxic gas and its synthesis from $\mathrm{P}_{4}$ requires harsh reaction conditions. ${ }^{2-3}$ To bypass $\mathrm{PCl}_{3}$ and $\mathrm{PH}_{3}$, tremendous efforts have been devoted into investigating direct functionalization of $\mathrm{P}_{4},{ }^{4}$ whose industrial production is on a scale of more than $10^{6}$ tons per year. However, preparation of OPCs directly from $\mathrm{P}_{4}$ remains extremely challenging; they generally suffer from low selectivity and conversion efficiency or only lead to partial breakup of the $\mathrm{P}_{4}$ tetrahedron. ${ }^{5} \mathrm{~A}$ recent breakthrough by the group of Wolf disclosed that the direct catalytic transformation of $\mathrm{P}_{4}$ into arylphosphines and phosphonium salts via photo-redox catalysis. ${ }^{6}$

Development of phosphorus transfer reagents other than $\mathrm{PCl}_{3}$ and $\mathrm{PH}_{3}$ is a promising strategy for the syntheses of OPCs and other value-added phosphorus-containing chemicals. To this end, Cummins and co-workers demonstrated the bis(trichlorosilyl)phosphide anion $\left[\mathrm{P}\left(\mathrm{SiCl}_{3}\right)_{2}\right]^{-}(\mathbf{A})$ (Figure 1a) derived from phosphates capable of producing OPCs. ${ }^{7}$ The Grützmacher and Goicoechea groups independently synthesized a large array of phosphorus frameworks via the 2-phosphaethynolate anion $[\mathrm{PCO}]^{-}(\mathbf{B}) .{ }^{8}$ More recently, Wolf et. al. reported the synthesis of monophosphines from hydrostannyl phosphines $\left(\mathrm{Bu}_{3} \mathrm{Sn}_{\mathrm{x}} \mathrm{PH}_{3-\mathrm{x}}(\mathrm{x}=1-3)(\mathbf{C})\right.$ resulting from the direct activation of $\mathrm{P}_{4}$ with stannyl radicals. ${ }^{9}$ Although chemical reactions for $\mathrm{P}_{4}$ activation have been explored in depth over the past decades, practical electrochemical activation of $\mathrm{P}_{4}$ is still in its infancy. ${ }^{10}$ The electrocatalytic $\mathrm{C}-\mathrm{P}$ bond formation using transition metal catalysts with sacrificial metal electrodes as reducing reagents have been reported. ${ }^{10}$
(a)

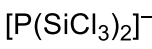
$[\mathrm{PCO}]^{-}$
$\left(\mathrm{Bu}_{3} \mathrm{Sn}\right)_{\mathrm{x}} \mathrm{PH}_{3-\mathrm{x}}$
A
B
C $(x=1-3)$
(b)

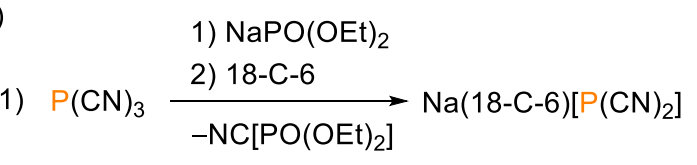
2)
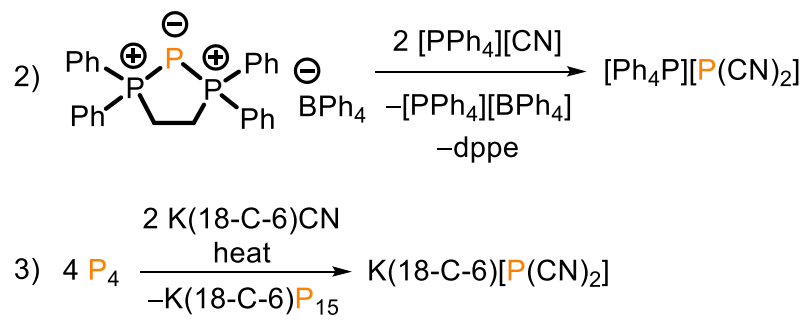

(c) This work:

$$
1 / 4 \mathrm{P}_{4}+\mathrm{HCN}+\mathrm{LiCN} \frac{\mathrm{RT},-\mathrm{H}_{2}}{\longrightarrow} \mathrm{Li}\left[\mathrm{P}(\mathrm{CN})_{2}\right] \longrightarrow \text { OPCs }
$$

Ambient conditions; High yield; Atom economy; Undivided cell

Figure 1. (a) Selected examples of phosphorus transfer reagents. (b) Known methods to generate $\left[\mathrm{P}(\mathrm{CN})_{2}\right]^{-}$. (c) Electrochemical synthesis of $\left[\mathrm{P}(\mathrm{CN})_{2}\right]^{-}$from $\mathrm{P}_{4}$.

The isolation of the dicyanophosphide anion salt $\mathrm{Na}(18-\mathrm{C}$ 6) $\left[\mathrm{P}(\mathrm{CN})_{2}\right](18-\mathrm{C}-6=18$-crown-6) dates back to 1977 by the group of Schmidpeter but its chemistry has been scarcely investigated likely due to the lack of efficient synthetic routes for large scale syntheses (Figure 1b). ${ }^{11}$ The known procedures include the reduction of $\mathrm{P}(\mathrm{CN})_{3}$ with $\mathrm{NaPO}(\mathrm{OEt})_{2},{ }^{11 \mathrm{a}}$ the ligand exchange of [dppeP] $\left[\mathrm{BPh}_{4}\right]$ [dppe $=$ bis(diphenylphosphino)ethane $]$ with cyanides and the disproportionation of $\mathrm{P}_{4}$ with $\mathrm{K}(18-\mathrm{C}-6) \mathrm{CN} .{ }^{12}$ These are typically associated with low efficiency and poor atom economy. A handful of reports described the displacement of the cyano 
groups of $\left[\mathrm{P}(\mathrm{CN})_{2}\right]^{-}$by carbon- or/and phosphorus-based anionic nucleophiles and the halide substitution of 2-chloro imidazolium salts and alkyl iodides. ${ }^{13}$

We herein present the facile synthesis of $\left[\mathrm{P}(\mathrm{CN})_{2}\right]^{-}$via electrochemical activation of $\mathrm{P}_{4}$ at room temperature using hydrogen cyanide $(\mathrm{HCN})$ as the oxidant in an undivided cell (Figure 1c). The electronic structure of $\left[\mathrm{P}(\mathrm{CN})_{2}\right]^{-}$is examined by DFT calculations. The utility of $\left[\mathrm{P}(\mathrm{CN})_{2}\right]^{-}$towards neutral and anionic carbon-based nucleophiles selectively affords scarcely accessible OPCs, such as cyano-phosphinidenes, cyclophosphanes and phospholides. These pave a straightforward path for facile bridging of OPCs from $\mathrm{P}_{4}$.

The nucleophilic disproportionation of $\mathrm{P}_{4}$ by $\mathrm{K}(18-\mathrm{C}-6) \mathrm{CN}$ in boiling $\mathrm{MeCN}$ can generate $\mathrm{K}(18-\mathrm{C}-6)\left[\mathrm{P}(\mathrm{CN})_{2}\right]$ but at the cost of losing 15 equivalents of phosphorus (Figure $1 \mathrm{~b}$ ). ${ }^{12 \mathrm{~b}} \mathrm{We}$ hypothesized that the controlled oxidation of $\mathrm{P}_{4}$ in the presence of cyanides might selectively afford $\left[\mathrm{P}(\mathrm{CN})_{2}\right]^{-}$. Specifically, electrochemical methods may be able to delicately control the oxidation from $\mathrm{P}(0)$ to $\mathrm{P}(+1)$ with the proper voltage. Hydrogen cyanide $(\mathrm{HCN})$, which is industrially produced, was postulated to work as the electrochemical oxidant and a cyanide source. ${ }^{14}$ However, to avoid the direct handling of $\mathrm{HCN}$ gas the combination of $\mathrm{Me}_{3} \mathrm{SiCN}$ with $\mathrm{LiOH}$ as a $\mathrm{HCN}$ surrogate was employed. This reaction also generated $\mathrm{LiCN}$ and $\left(\mathrm{Me}_{3} \mathrm{Si}\right)_{2} \mathrm{O}$ (Figure S2) and the former provides another equivalent of cyanide needed for the subsequent electrolysis. Note that $\mathrm{Me}_{3} \mathrm{SiCN}$ (bp $118^{\circ} \mathrm{C}$ ) is a toxic liquid which releases highly toxic $\mathrm{HCN}$ gas upon contact with moisture.

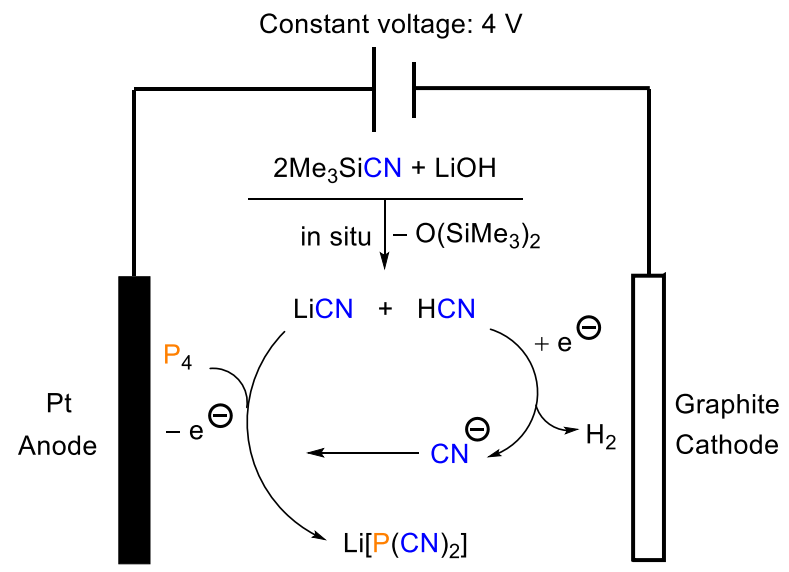

Figure 2. Electro-oxidation of $\mathrm{P}_{4}$ to $\operatorname{Li}\left[\mathrm{P}(\mathrm{CN})_{2}\right]$.

An undivided cell at room temperature was equipped with graphite and platinum electrodes as the respective anode and cathode. Then a THF solution of $\mathrm{P}_{4}(0.125 \mathrm{mmol}), \mathrm{Me}_{3} \mathrm{SiCN}(1.67 \mathrm{mmol})$ and $\mathrm{LiOH}(0.75 \mathrm{mmol})$ was subjected to electrolysis at $4 \mathrm{~V}$ voltage (Figure 2). ${ }^{31} \mathrm{P}$ NMR analysis of the aliquots of the reaction mixture indicated the selective conversion of $\mathrm{P}_{4}$ to $\left[\mathrm{P}(\mathrm{CN})_{2}\right]^{-}(-196.8 \mathrm{ppm})$ and no other phosphorus-containing products or intermediates were observed. The electrolysis was complete within $20 \mathrm{~h}$ and subsequent workup with dioxane gave $\mathrm{Li}(\text { dioxane })_{\mathrm{x}}\left[\mathrm{P}(\mathrm{CN})_{2}\right](\mathrm{x}=1.1)$ as an analytically pure product in $92 \%$ yield. The $\mathrm{x}$ value of 1.1 was determined by ${ }^{1} \mathrm{H}$ NMR spectroscopic studies using an internal standard and corroborated by elemental analysis. The $\mathrm{x}$ value varied depending on the drying time under vacuum. This is similar to the observations for the salt compound $\mathrm{Na}$ (dioxane) ${ }_{x}[\mathrm{OCP}]$ by Grützmacher et al. ${ }^{15}$ It is important to note that the reaction can be scaled up to make grams of $\operatorname{Li}(\text { dioxane })_{1.0}\left[\mathrm{P}(\mathrm{CN})_{2}\right](\mathbf{1})(1.96 \mathrm{~g})$ at $5.0 \mathrm{mmol}$ scale of $\mathrm{P}_{4}$ although with relatively lower yield $(55 \%)$. No contamination of LiCN was observed by IR spectroscopy. This batch of $\mathbf{1}$ was used for the reactivity studies.
No conversion was observed after stirring the same mixture for $10 \mathrm{~h}$ without electrolysis. In the presence of $50 \% \mathrm{~mol} \mathrm{LiCN}$, complete conversion of $\mathrm{P}_{4}$ took a shorter time $(10 \mathrm{~h})$ and gave a similar yield. Mechanistically, $\mathrm{P}_{4}$ is formally oxidized to form $\left[\mathrm{P}(\mathrm{CN})_{2}\right]^{-}$ on the anode and $\mathrm{HCN}$ is reduced to dihydrogen on the cathode. Alternatively, cyanide anion is oxidized to form transient cyano radicals or dicyan, which react with $\mathrm{P}_{4}$ under electrolysis to eventually give $\left[\mathrm{P}(\mathrm{CN})_{2}\right]^{-6}{ }^{6,9}$ Gas bubbles (i.e. $\mathrm{H}_{2}$ ) was observed from the Pt electrode during the electrolysis. An analogous reaction using $\mathrm{MeCN}$ as solvent gave the same product and the formation of hydrogen was observed by ${ }^{1} \mathrm{H}$ NMR spectroscopy (Figure S4). A similar redox reaction occurred via the combination of $\mathrm{P}_{4}$ with $\mathrm{Me}_{3} \mathrm{SiCN}$ under the same conditions and the byproduct $\left(\mathrm{Me}_{3} \mathrm{Si}\right)_{2}$ was observed by ${ }^{1} \mathrm{H}$ NMR spectroscopy (Figure S5). While we were able to observe the generation of $\mathrm{M}\left[\mathrm{P}(\mathrm{CN})_{2}\right](\mathrm{M}=\mathrm{K}, \mathrm{Na})$ using $\mathrm{KOH}$ or $\mathrm{NaOH}$, instead of $\mathrm{LiOH}$, the lack of appropriate electrolytes to maintain the conductivity obscures the isolation of analytically pure $\mathrm{M}\left[\mathrm{P}(\mathrm{CN})_{2}\right]$.
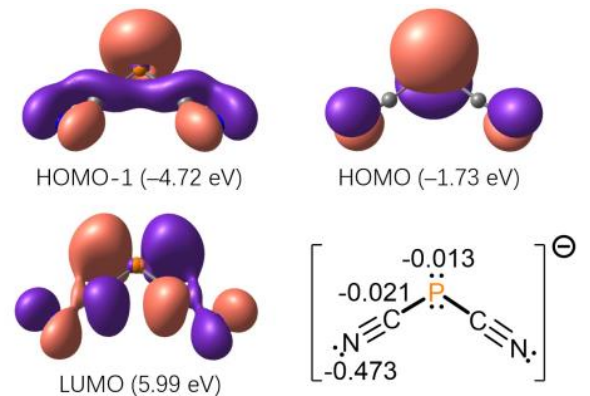

Figure 3. Frontier orbitals and NPA charge distribution of $\left[\mathrm{P}(\mathrm{CN})_{2}\right]^{-}$.

The electronic structure of the $\left[\mathrm{P}(\mathrm{CN})_{2}\right]^{-}$anion was probed by density functional theory (DFT) calculations (M06-2X/def2-SVP) (Figure 3$)$. While the $\mathrm{C}-\mathrm{N}$ bond lengths $(1.173 \AA$ ) and $\mathrm{C}-\mathrm{P}-\mathrm{C}$ bond angle $\left(97.4^{\circ}\right)$ in the optimized structure of $\left[\mathrm{P}(\mathrm{CN})_{2}\right]^{-}$are comparable to the solid-state structure of $\mathrm{K}(18-\mathrm{C}-6) \mathrm{P}(\mathrm{CN})_{2}(1.140 \AA$ av.; $\left.95.22^{\circ}\right),{ }^{12 \mathrm{c}}$ the computed $\mathrm{P}-\mathrm{C}$ bond lengths $(1.779 \AA$ each) are longer than those in the solid-state structure (1.692 $\AA$ and $1.666 \AA$ ) (Figure S101), probably due to the crystal packing effects. The HOMO-1 $(-4.72 \mathrm{eV})$ and HOMO $(-1.73 \mathrm{eV})$ are predominantly the in-plane and out-of-plane $\mathrm{P}$ lone pairs, respectively, while the LUMO exhibits features of $\pi^{*}$ orbitals over the anion with the major contribution of $\mathrm{P}$. The natural population analysis (NPA) (M062X/def2-TZVP) reveals that the anionic charges are considerably located at two $\mathrm{N}$ atoms $(-0.47$ a.u.) whereas the $\mathrm{P}$ atom bears almost no net charge ( -0.01 a.u.). The Wiberg bond indices (WBIs) of $\mathrm{P}-\mathrm{C}$ and $\mathrm{C}-\mathrm{N}$ bonds are 1.1 and 2.8 , respectively. Collectively, these results demonstrate the ambiphilic nature of $\mathrm{P}$. 


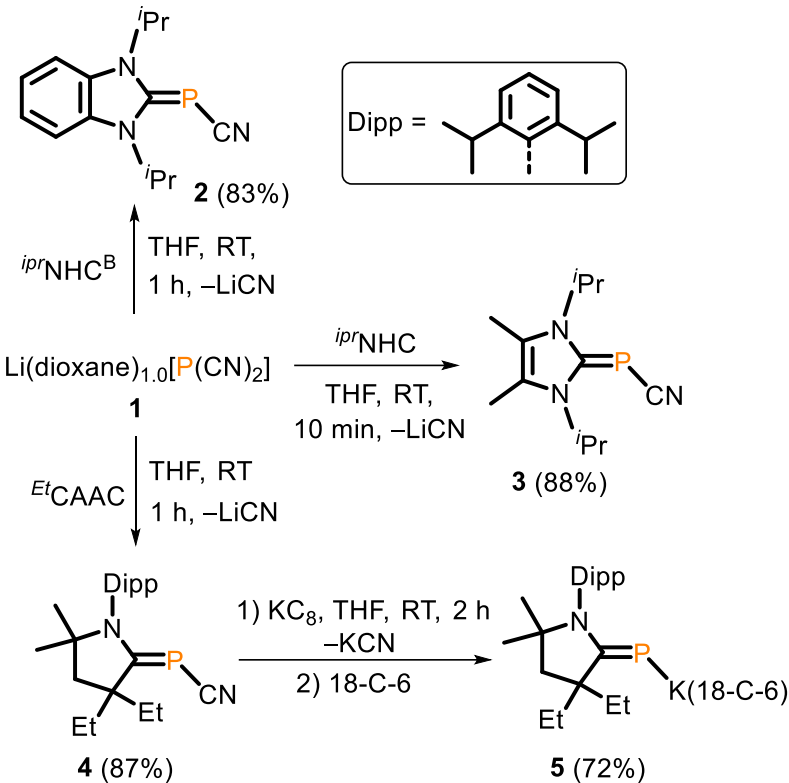

Figure 4. Synthesis of phosphinidenes from $\left[\mathrm{P}(\mathrm{CN})_{2}\right]^{-}$and the reduction of 4. ${ }^{i p r} \mathrm{NHC}=\mathrm{N}, \mathrm{N}^{\prime}$-diisopropyl-4,5-dimethyl-2-ylidene; ${ }^{i p r} \mathrm{NHC}^{\mathrm{B}}=\mathrm{N}, \mathrm{N}$-diisopropylbenzimidazolylidene; ${ }^{E t} \mathrm{CAAC}=2,6$ diisopropylphenyl-4,4-diethyl-2,2-dimethyl-pyrrolidin-5-ylidene.

We then investigated the synthetic potential of $\left[\mathrm{P}(\mathrm{CN})_{2}\right]^{-}$for OPCs using carbon-based nucleophiles. Albeit the $\left[\mathrm{P}(\mathrm{CN})_{2}\right]^{-}$has an overall anionic nature, treatment of $\mathbf{1}$ with various neutral carbon nucleophiles [i.e. N-heterocyclic carbene (NHC) and cyclic(alkyl)(amino)carbene (CAAC)] gave base-stabilized phosphinidenes 2-4 (Figure 4), concurrent with the elimination of LiCN. The ${ }^{31} \mathrm{P}$ NMR spectra of $\mathbf{2}, \mathbf{3}$ and $\mathbf{4}$ consist of a singlet at $-133.7,-153.8$ and $-55.8 \mathrm{ppm}$ in $\mathrm{C}_{6} \mathrm{D}_{6}$, respectively. Further confirmation of structures of 2-4 was carried out with single crystal X-ray diffraction (Figures 5a, S16 and S17). A close related compound of 2 with methyl substituents on the N-heterocycle was reported by Schmidpeter. ${ }^{13 a}$ The formation of 2-4 indicates the facile replacement of LiCN with nucleophilic carbenes, reminiscent of examples of ligand exchange reactions at a phosphinidene described by Bertrand et al. ${ }^{16}$ Notably, while the chemistry of base-stabilized phosphinidenes is quite rich, their syntheses usually require multiple steps and relatively harsh conditions. ${ }^{17}$ Our synthetic route represents a two-step procedure accessing rare examples of cyano-substituted phosphinidenes from $\mathrm{P}_{4}$.

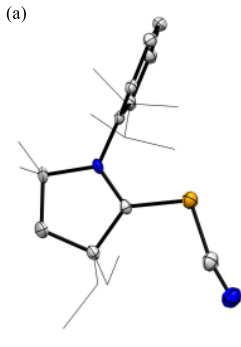

(c)

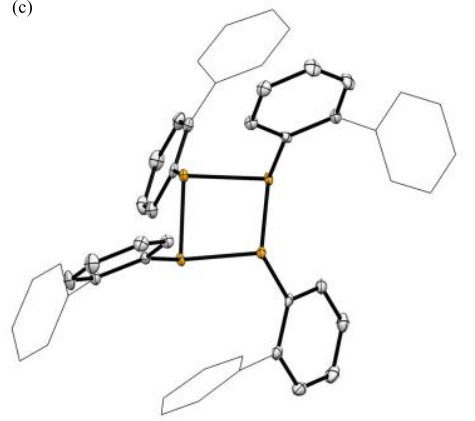

(b)

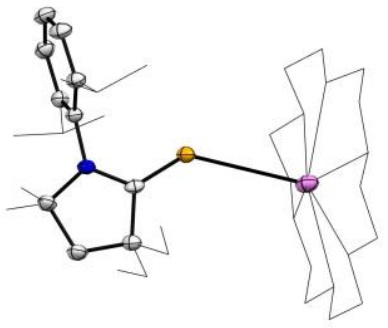

(d)
Figure 5. Solid-state structures of 4 (a), 5 (b), 10 (c) and 15' (d). C: grey; N: blue; P: orange; S: yellow; K: violet; Na: purple. Hydrogen atoms and solvent molecules are omitted for clarity. Thermal ellipsoids are set at the $40 \%$ probability level.

In addition, reduction of $\mathbf{4}$ with excess $\mathrm{KC}_{8}$ at ambient temperature in THF for $2 \mathrm{~h}$ followed by addition of $18-\mathrm{C}-6$ afforded species 5 (Figure 4), which was after workup isolated as an orange solid. The ${ }^{31} \mathrm{P}$ NMR resonance of $\mathbf{5}(230.2 \mathrm{ppm})$ is high-frequency shifted relative to those observed for $\left[{ }^{\mathrm{Me}} \mathrm{CAAC}=\mathrm{PLi}\right]_{2}(179.3 \mathrm{ppm})^{18}$ and $\left[{ }^{\mathrm{Cy}} \mathrm{CAAC}=\mathrm{PK}\right]_{2}(206.9 \mathrm{ppm}) .{ }^{19} \mathrm{In}$ contrast to the dimeric structures of $\left[{ }^{\mathrm{Me}} \mathrm{CAAC}=\mathrm{PLi}\right]_{2}$ and $\left[{ }^{\mathrm{cy}} \mathrm{CAAC}=\mathrm{PK}\right]_{2}, \mathbf{5}$ represents a rare example of a monomeric carbene-stabilized $\mathrm{P}^{-}$anion (Figure $5 \mathrm{~b}$ ). The conversion of $\left[\mathrm{P}(\mathrm{CN})_{2}\right]^{-}$to $\left[{ }^{\mathrm{Et}} \mathrm{CAAC}=\mathrm{P}\right]^{-}$can be viewed as a formal "P $\mathrm{P}$ " anion delivery to carbenes, and thus showcases huge potential of $\left[\mathrm{P}(\mathrm{CN})_{2}\right]^{-}$for $\mathrm{P}$ atom transfer reactions. Nonetheless, the formation of $\mathbf{5}$ is unique as the analogous reaction of $\mathbf{2}$ or $\mathbf{3}$ with $\mathrm{KC}_{8}$ is apparently inert.

Next, attempts to efficiently synthesize cyclophosphanes were undertaken (Figure 6). These species with a small $P_{n}(n=2-5)$ ring are usually prepared via reduction reactions of mono-substituted phosphorus dichlorides with undesirable reagents (e.g. alkalineearth reductants), which typically suffer from low chemoselectivity and operational complexity for purification. ${ }^{20}$ Dropwise addition of ${ }^{t} \mathrm{BuLi}$ to a THF solution of $\mathbf{1}$ at $-35^{\circ} \mathrm{C}$ forms an intermediate $6\left({ }^{31} \mathrm{P}\right.$ NMR: $-90.0 \mathrm{ppm}$ ) that upon warming up to room temperature smoothly converted into two products $\left({ }^{t} \mathrm{BuP}\right){ }_{3} 7\left({ }^{31} \mathrm{P}\right.$ NMR: -70.5 and $-109.5 \mathrm{ppm})$ and $\left({ }^{t} \mathrm{BuP}\right)_{4} 8\left({ }^{31} \mathrm{P} \mathrm{NMR}:-57.5 \mathrm{ppm}\right)$ in a molar ratio of $1: 1 .^{21}$ Heating the reaction mixture at $70{ }^{\circ} \mathrm{C}$ for $24 \mathrm{~h}$ resulted in complete conversion into $\mathbf{8}$. As early work by Schmidpeter and co-workers described the reaction of $\mathrm{K}\left[\mathrm{P}(\mathrm{CN})_{2}\right]$ with PhLi leading to an equilibrium of $\mathrm{M}[\mathrm{PhPCN}](\mathrm{M}=\mathrm{Li}$ or $\mathrm{K})$ and the pentaphenyl pentaphospholane $(\mathrm{PhP})_{5},{ }^{13 \mathrm{c}}$ the cyanide anion in the reaction mixture is proposed to promote the transformation of $\mathbf{7}$ to $\mathbf{8}$. As Baudler et al. reported in 1984, in the absence of cyanide the thermal arrangement of $\mathbf{7}$ to $\mathbf{8}$ requires much higher temperatures (i.e. 200 $\left.{ }^{\circ} \mathrm{C}\right){ }^{22}$ In a similar vein, we reacted $\operatorname{ArLi}(\mathrm{Ar}=1,1$ '-biphenyl-2-yl) (9) with $\mathbf{1}$ at room temperature to give $(\mathrm{ArP})_{4} \mathbf{1 0}$ in $82 \%$ yield (Figures $5 c$ and $6 b)$. In this case, no cyclotriphosphane $(\operatorname{ArP})_{3}$ was observed. 
(a)

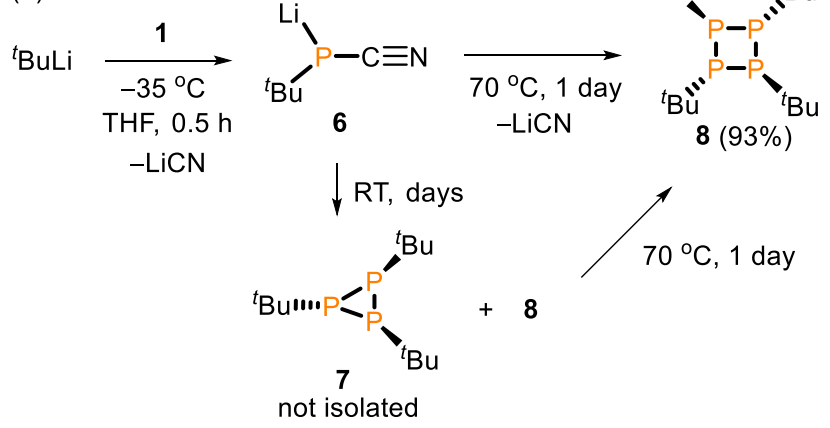

(b)

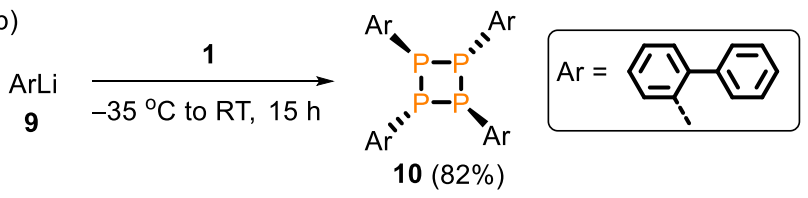

Figure 6. Synthesis of cyclophosphanes from $\left[\mathrm{P}(\mathrm{CN})_{2}\right]^{-}$.

Phospholides featuring an anionic unsaturated five-membered $\mathrm{P}_{1} \mathrm{C}_{4}$ ring have received tremendous interest in the past decades due to the fundamental significance of the structural and electronic properties as well as their applications in synthetic chemistry. ${ }^{23} \mathrm{We}$ envisioned the likelihood that the simple reaction of $\left[\mathrm{P}(\mathrm{CN})_{2}\right]^{-}$with organo-dilithium reagents would furnish phospholides, which are versatile precursors for synthesis of phosphole-based materials. ${ }^{24}$ Gratifyingly, addition of $\mathbf{1}$ to the respective dilithium reagents gave rise to the corresponding phospholides 13-15 as a single P-containing product (Figure 7). 13-15 were isolated in moderate to good yield (56\%-94\%). Although X-ray quality single crystals of the lithium salts have not been obtained, the connectivity of the phospholides was further authenticated by X-ray diffraction with the analogous sodium salts 13'-15' derived from $\mathrm{Na}(18-\mathrm{C}-6)\left[\mathrm{P}(\mathrm{CN})_{2}\right]$ (Figures 5d, S21 and S22). The synthetic method presented herein provides access to phospholides from $\mathrm{P}_{4}$ in a two-step fashion via $\left[\mathrm{P}(\mathrm{CN})_{2}\right]^{-}$as a bridge. It is important to note that the current protocols for phospholides generation require multistep synthesis, involving the use of phosphorus trihalides. ${ }^{25}$ Zhang et al. reported the direct facile synthesis of phospholides from $\mathrm{P}_{4}$ but with low $\mathrm{P}$ atom economy (theoretically loss of $75 \% \mathrm{P}$ atoms). ${ }^{5 \mathrm{~g}, 5 \mathrm{~m}, 26}$<smiles>CC(C(Cl)=C(c1ccccc1)c1ccccc1)c1ccccc1</smiles>

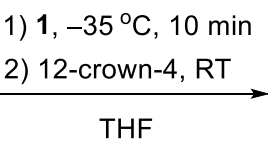

11

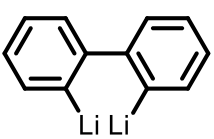

12
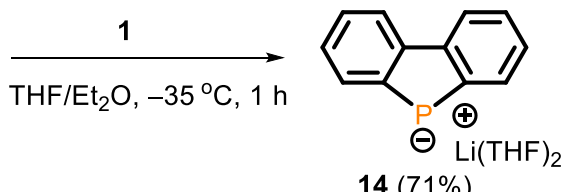

$14(71 \%)$

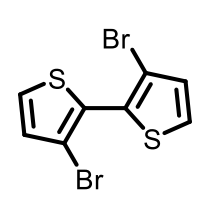

1) $4^{t} \mathrm{BuLi},-54^{\circ} \mathrm{C}, 1 \mathrm{~h}$

2) $1,-35^{\circ} \mathrm{C}, 0.5 \mathrm{~h}$

3) 12-crown-4, RT

$\mathrm{THF} / \mathrm{Et}_{2} \mathrm{O} / \mathrm{DME}$

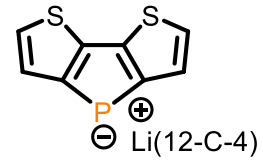

$15(94 \%)$
Figure 7. Synthesis of phospholides from $\left[\mathrm{P}(\mathrm{CN})_{2}\right]^{-}$.
To conclude, we have showcased a practical versatile approach for the conversion of $\mathrm{P}_{4}$ into useful OPCs with high $\mathrm{P}$ atom economy via $\left[\mathrm{P}(\mathrm{CN})_{2}\right]^{-}$, exemplified by the effective synthesis of basestabilized cyano-phosphinidenes 2-4, cyclophosphanes $\mathbf{8}$ and $\mathbf{1 0}$, and phospholides 13-15. Importantly, this anion is readily available from an electrochemical activation of $\mathrm{P}_{4}$ on a gram scale. The practical simplicity of our strategy may spur considerable interest in development of $\left[\mathrm{P}(\mathrm{CN})_{2}\right]^{-}$that has been relatively dormant for many years. The utility of this approach directly from $\mathrm{P}_{4}$ to construct other useful OPCs as well as unusual inorganic/organic phosphorus skeletons are the subject of ongoing work.

\section{Supporting Information}

The Supporting Information is available free of charge at https://pubs.acs.org/doi/10.1021/XXXXXX.

Synthesis procedures for the compounds, NMR spectroscopic and $\mathrm{X}$-ray characterization of the compounds, and computational details (PDF)

\section{AUTHOR INFORMATION}

\section{Corresponding Author}

Liu Leo Liu

E-mail: liuleoliu@ sustech.edu.cn

Notes

The authors declare no competing financial interests.

\section{ACKNOWLEDGMENT}

This work is dedicated to Prof. Yufen Zhao. We gratefully acknowledge financial support from the National Natural Science Foundation of China (22101114), SUSTech startup fund (Y01216248) and China Postdoctoral Science Foundation (2021M691420). The theoretical work is supported by the Center for Computational Science and Engineering and CHEM High-Performance Supercomputer Cluster located in the Department of Chemistry at SUSTech. We acknowledge the assistance of SUSTech Core Research Facilities. We thank Drs. Xiaoyong Chang, Yuhui Hua, Zhe Huang and Rui Wei for helpful discussions and assistance in X-ray diffraction analyses. Prof. Chuan He and Dr. Jie $\mathrm{Ke}$ are thanked for assistance in electrolysis experiments. We thank Prof. Xin $\mathrm{Xu}$ at Soochow University for assistance in elemental analysis. We thank Profs. Yufen Zhao and Guo Tang for providing $\mathrm{P}_{4}$. We thank Dr. D. A. Ruiz for valuable discussion.

\section{REFERENCES:}

1. (a) De Boer, M. A.; Wolzak, L.; Slootweg, J. C., Phosphorus: reserves, production, and applications. In Phosphorus Recovery and Recycling, Springer: 2019; pp 75-100; (b) Corbridge, D. E., Phosphorus: chemistry, biochemistry and technology, 6th ed.;. CRC press: 2016; pp 11473; (c) Dietliker, K.; Jung, T.; Benkhoff, J.; Kura, H.; Matsumoto, A.; Oka, H.; Hristova, D.; Gescheidt, G.; Rist, G., New Developments in Photoinitiators. Macromol. Symp. 2004, 217, 77-98.

2. (a) Bettermann, G.; Krause, W.; Riess, G.; Hofmann, T., Phosphorus compounds, inorganic. In Ullmann's Encyclopedia of Industrial Chemistry, Wiley: 2000; pp 1-18; (b) Geeson, M. B.; Cummins, C. C., Let's Make White Phosphorus Obsolete. ACS Cent. Sci. 2020, 6, 848-860.

3 . Weferling, N.; Zhang, S. M.; Chiang, C. H., Commercial organophosphorus chemicals: status and new developments. Procedia Engineering 2016, 138, 291-301.

4. (a) Barton, D. H. R.; Zhu, J., Elemental white phosphorus as a radical trap: a new and general route to phosphonic acids. J. Am. Chem. Soc. 
1993, 115, 2071-2072; (b) Barton, D. H. R.; Vonder Embse, R. A., The invention of radical reactions. Part 39. The reaction of white phosphorus with carbon-centered radicals. An improved procedure for the synthesis of phosphonic acids and further mechanistic insights. Tetrahedron 1998, 54, 12475-12496; (c) Cossairt, B. M.; Cummins, C. C., Radical synthesis of trialkyl, triaryl, trisilyl and tristannyl phosphines from P4. New J. Chem. 2010, 34, 1533-1536; (d) Cossairt, B. M.; Piro, N. A.; Cummins, C. C., Early-transition-metal-mediated activation and transformation of white phosphorus. Chem. Rev. 2010, 110, 4164-4177; (e) Caporali, M.; Gonsalvi, L.; Rossin, A.; Peruzzini, M., P4 activation by late-transition metal complexes. Chem. Rev. 2010, 110, 4178-4235; (f) Scheer, M.; Balazs, G.; Seitz, A., P4 activation by main group elements and compounds. Chem. Rev 2010, 110, 4236-4256; (g) Martin, D.; Soleilhavoup, M.; Bertrand, G. Stable singlet carbenes as mimics for transition metal centers. Chem. Sci. 2011, 2, 389-399; (h) Giffin, N. A.; Masuda, J. D., Reactivity of white phosphorus with compounds of the p-block. Coord. Chem. Rev. 2011, 255, 1342-1359; (i) Khan, S.; Sen, S. S.; Roesky, H. W., Activation of phosphorus by group 14 elements in low oxidation states. Chem. Commun. 2012, 48, 2169-2179; (j) Holthausen, M. H.; Weigand, J. J., The chemistry of cationic polyphosphorus cages-syntheses, structure and reactivity. Chem Soc. Rev. 2014, 43, 6639-6657; (k) Borger, J. E.; Ehlers, A. W.; Slootweg, J. C.; Lammertsma, K., Functionalization of P4 through Direct P-C Bond Formation. Chem. Eur. J. 2017, 23, 11738-11746; (1) Ghosh, S. K. Cummins, C. C.; Gladysz, J. A., A direct route from white phosphorus and fluorous alkyl and aryl iodides to the corresponding trialkyl- and triarylphosphines. Org. Chem. Front. 2018, 5, 3421-3429; (m) Huangfu, X.; Zhang, Y.; Chen, P.; Lu, G.; Cao, Y.; Tang, G.; Zhao, Y., Synthesis of mixed phosphorotrithioates from white phosphorus. Green Chem. 2020, 22, 8353-8359; (n) Giusti, L.; Landaeta, V. R.; Vanni, M.; Kelly, J. A.; Wolf, R.; Caporali, M., Coordination chemistry of elemental phosphorus. Coord. Chem. Rev. 2021, 441, 213927.

5. (a) Masuda, J. D.; Schoeller, W. W.; Donnadieu, B.; Bertrand, G., Carbene Activation of P4 and Subsequent Derivatization. Angew. Chem. Int. Ed. 2007, 46, 7052-7055; (b) Masuda, J. D.; Schoeller, W. W.; Donnadieu, B.; Bertrand, G., NHC-Mediated Aggregation of P4: Isolation of a P12 Cluster. J. Am. Chem. Soc. 2007, 129, 14180-14181; (c) Tofan, D.; Cummins, C. C., Photochemical Incorporation of Diphosphorus Units into Organic Molecules. Angew. Chem., Int. Ed. 2010, 49, 7516-7518; (d) Dorsey, C. L.; Squires, B. M.; Hudnall, T. W., Isolation of a Neutral P8 Cluster by [2+2] Cycloaddition of a Diphosphene Facilitated by Carbene Activation of White Phosphorus. Angew. Chem., Int. Ed. 2013, 52, 4462 4465; (e) Heinl, S.; Reisinger, S.; Schwarzmaier, C.; Bodensteiner, M. Scheer, M., Selective Functionalization of P4 by Metal-Mediated C-P Bond Formation. Angew. Chem., Int. Ed. 2014, 53, 7639-7642; (f) Borger, J. E.; Ehlers, A. W.; Lutz, M.; Slootweg, J. C.; Lammertsma, K. Functionalization of P4 Using a Lewis Acid Stabilized Bicyclo[1.1.0]tetraphosphabutane Anion. Angew. Chem., Int. Ed. 2014, 53 , 12836-12839; (g) Xu, L.; Chi, Y.; Du, S.; Zhang, W. X.; Xi, Z., Direct synthesis of phospholyl lithium from white phosphorus. Angew. Chem., Int. Ed. 2016, 55, 9187-9190; (h) Du, S.; Yin, J.; Chi, Y.; Xu, L.; Zhang, W X., Dual Functionalization of White Phosphorus: Formation, Characterization, and Reactivity of Rare - Earth - Metal Cyclo - P3 Complexes. Angew. Chem., Int. Ed. 2017, 56, 15886-15890; (i) Borger, J. E.; Ehlers, A. W.; Lutz, M.; Slootweg, J. C.; Lammertsma, K., Selective [3+1] Fragmentations of P4 by "P" Transfer from a Lewis Acid Stabilized [RP4]-Butterfly Anion. Angew. Chem., Int. Ed. 2017, 56, 285-290; (j) Seitz A. E.; Hippauf, F.; Kremer, W.; Kaskel, S.; Scheer, M., Facile storage and release of white phosphorus and yellow arsenic. Nat. Commun. 2018, 9, 361 (k) Lu, W.; Xu, K.; Li, Y.; Hirao, H.; Kinjo, R., Facile Activation of Homoatomic $\sigma$ Bonds in White Phosphorus and Diborane by a Diboraallene. Angew. Chem., Int. Ed. 2018, 57, 15691-15695; (1) Du, S.; Yang, J.; Hu, J.; Chai, Z.; Luo, G.; Luo, Y.; Zhang, W.-X.; Xi, Z., Direct Functionalization of White Phosphorus to Cyclotetraphosphanes: Selective Formation of Four P-C Bonds. J. Am. Chem. Soc. 2019, 141, 6843-6847; (m) Du, S.; Hu, J.; Chai, Z.; Zhang, W.-X.; Xi, Z., Isolation and Characterization of Four Phosphorus Cluster Anions P73-, P144-, P162and P264- from the Nucleophilic Functionalization of White Phosphorus with 1,4-Dilithio-1,3-butadienes. Chin. J. Chem. 2019, 37, 71-75; (n) Zhang, F.; Zhang, J.; Chen, Z.; Weng, L.; Zhou, X., An Yttrium Organic cycloP4 Complex and Its Selective Conversions. Inorg. Chem. 2019, 58, 84518459; (o) Du, S.; Chai, Z.; Hu, J.; Zhang, W.-X.; Xi, Z., Isolation and Characterization of a Trinuclear Rare-Earth Metal Complex Containing a Bicyclo[3.1.0]-P<sub $>6</$ sub $><$ sup $>4-</$ sup $>$ Ligand. Chin. J. Org. Chem 2019, 39, 2338-2342.
6. (a) Lennert, U.; Arockiam, P. B.; Streitferdt, V.; Scott, D. J Rödl, C.; Gschwind, R. M.; Wolf, R., Direct catalytic transformation of white phosphorus into arylphosphines and phosphonium salts. Nat. Catal. 2019, 2, 1101-1106; (b) Rothfelder, R.; Streitferdt, V.; Lennert, U.; Cammarata, J.; Scott, D. J.; Zeitler, K.; Gschwind, R. M.; Wolf, R., Photocatalytic Arylation of P4 and PH3: Reaction Development Through Mechanistic Insight. Angew. Chem., Int. Ed. 2021, 60, 24650-24658; (c) Till, M.; Streitferdt, V.; Scott, D. J.; Mende, M.; Gschwind, R. M.; Wolf, R., Photochemical transformation of chlorobenzenes and white phosphorus into arylphosphines and phosphonium salts. Chem. Commun. 2022, DOI: 10.1039/D1CC05691C

7. (a) Geeson, M. B.; Cummins, C. C., Phosphoric acid as a precursor to chemicals traditionally synthesized from white phosphorus. Science 2018, 359, 1383-1385; (b) Geeson, M. B.; Ríos, P.; Transue, W. J.; Cummins, C. C., Orthophosphate and Sulfate Utilization for C-E (E = P, S) Bond Formation via Trichlorosilyl Phosphide and Sulfide Anions. J. Am Chem. Soc. 2019, 141, 6375-6384.

$8 . \quad$ (a) Goicoechea, J. M.; Grützmacher, H., The Chemistry of the 2-Phosphaethynolate Anion. Angew. Chem., Int. Ed. 2018, 57, 16968 16994; (b) Weber, L., 2-Phospha- and 2-Arsaethynolates - Versatile Building Blocks in Modern Synthetic Chemistry. Eur. J. Inorg. Chem. 2018, 2018, 2175-2227.

9. Scott, D. J.; Cammarata, J.; Schimpf, M.; Wolf, R., Synthesis of monophosphines directly from white phosphorus. Nat. Chem. 2021, 13 458-464

10. (a) Kargin, Y. M.; Budnikova, Y. G., Electrochemistry of Organophosphorus Compounds. Russ. J. Gen. Chem. 2001, 71, 1393-1421; (b) Yakhvarov, D. G.; Gorbachuk, E. V.; Sinyashin, O. G., Electrode Reactions of Elemental (White) Phosphorus and Phosphane PH3. Eur. J. Inorg. Chem. 2013, 2013, 4709-4726; (c) Budnikova, Y. H.; Gryaznova, T. V.; Grinenko, V. V.; Dudkina, Y. B.; Khrizanforov, M. N., Eco-efficient electrocatalytic C-P bond formation. Pure Appl. Chem. 2017, 89, 311-330. 11. (a) Schmidpeter, A.; Zwaschka, F., Dicynophosphide. Angew Chem. Int. Ed. Engl. 1977, 16, 704-705; (b) Sheldrick, W. S.; Kroner, J.; Zwaschka, F.; Schmidpeter, A., Structure of the Dicyanophosphide Ion in a Crown-Ether Sodium Salt. Angew. Chem. Int. Ed. Engl. 1979, 18, 934-935. 12. (a) Binder, J. F.; Kosnik, S. C.; St Onge, P. B. J.; Macdonald, C. L. B., Synthesis of Heavy Dicyanamide Homologues from Air-Stable Precursors. Chem. Eur. J. 2018, 24, 14644-14648; (b) Schmidpeter, A.; Burget, G.; Chandler, D. J.; Jones, R. A., ([18] Crown - 6) Potassium Dicyanophosphide (1 - ). Inorg. Synth. 1989, 25, 126-129; (c) Schmidpeter, A.; Burget, G.; Zwaschka, F.; Sheldrick, W. S., Cyanphosphorverbindungen. IX. Cyanidabbau von weißem Phosphor zu Dicyanphosphiden und die Dicyanphosphid-Struktur. Z. Anorg. Allg. Chem. 1985, 527, 17-32

13. (a) Schmidpeter, A.; Gebler, W.; Zwaschka, F.; Sheldrick, W S., The PCN Group as a Pseudochalcogen; Cyanophosphinidene Substituted Heterocycles. Angew. Chem. Int. Ed. Engl. 1980, 19, 722-723; (b) Schmidpeter, A.; Bürget, G., Dicyanphosphid-Reaktionen [1]/Dicyanophosphide Reactions [1]. Z. Naturforsch. B 1985, 40, 13061313; (c) Schmidpeter, A.; Zirzow, K. H.; Burget, G.; Huttner, G.; Jibril, I., Cyanidabbau von (PhP) 5: Bildung, Struktur und Reaktionen des Phenyl - cyanphosphid - Ions. Chem. Ber. 1984, 117, 1695-1706; (d) Hoge, B.; Panne, P., Synthesis of a Functional C2 - Symmetrical Bidentate Diphenylphosphonite DIOP Derivative and Its Conversion into the Corresponding $\pi$ - Acidic Bis (pentafluorophenyl) and Bis (p tetrafluoropyridyl) Compounds. Chem. Eur. J. 2006, 12, 9025-9035.

14. (a) Fedurco, M.; Sartoretti, C. J.; Augustynski, J., Electrochemical Conversion of Cyanide into Methylamine and $\mathrm{C} 1-\mathrm{C} 2$ Hydrocarbons. J. Am. Chem. Soc. 1999, 121, 888-889; (b) Sawyer, D. T.; George, R. S.; Rhodes, R. C., Polarography of Gases. Quantitative Studies of Oxygen and Sulfur Dioxide. Anal. Chem. 1959, 31, 2-5.

15. Heift, D.; Benkő, Z.; Grützmacher, H., Coulomb repulsion versus cycloaddition: formation of anionic four-membered rings from sodium phosphaethynolate, $\mathrm{Na}(\mathrm{OCP})$. Dalton Trans. 2014, 43, 831-840. 16. Hansmann, M. M.; Bertrand, G., Transition-Metal-like Behavior of Main Group Elements: Ligand Exchange at a Phosphinidene. J. Am. Chem. Soc. 2016, 138, 15885-15888.

17. (a) Schwedtmann, K.; Zanoni, G.; Weigand, J. J., Recent Advances in Imidazoliumyl-Substituted Phosphorus Compounds. Chem. Asian J. 2018, 13, 1388-1405; (b) Krachko, T.; Slootweg, J. C., NHeterocyclic Carbene-Phosphinidene Adducts: Synthesis, Properties, and Applications. Eur. J. Inorg. Chem. 2018, 2018, 2734-2754. 
(a) Kundu, S.; Sinhababu, S.; Luebben, A. V.; Mondal, T.; Koley, D.; Dittrich, B.; Roesky, H. W., Reagent for Introducing BaseStabilized Phosphorus Atoms into Organic and Inorganic Compounds. $J$. Am. Chem. Soc. 2018, 140, 151-154; (b) Kundu, S.; Sinhababu, S.; Siddiqui, M. M.; Luebben, A. V.; Dittrich, B.; Yang, T.; Frenking, G.; Roesky, H. W., Comparison of Two Phosphinidenes Binding to Silicon(IV)dichloride as well as to Silylene. J. Am. Chem. Soc. 2018, 140, 9409-9412.

19. Kulkarni, A.; Arumugam, S.; Francis, M.; Reddy, P. G.; Nag, E.; Gorantla, S. M. N. V. T.; Mondal, K. C.; Roy, S., Solid-State Isolation of Cyclic Alkyl(Amino) Carbene (cAAC)-Supported Structurally Diverse Alkali Metal-Phosphinidenides. Chem. Eur. J. 2021, 27, 200-206.

20. Eilrich, V. J.; Hey-Hawkins, E., Cyclooligophosphanes and their coordination chemistry. Coord. Chem. Rev. 2021, 437, 213749.

21. Baudler, M.; Glinka, K.; Cowley, A. H.; Pakulski, M., Organocyclophosphanes. In Inorg. Synth., Wiley: 1989; pp 1-5.

22. Baudler, M.; Hahn, J.; Clef, E., Contributions to the Chemistry of Phosphorus. 139. Triethylcyclotriphosphane, Trimethylcyclotriphosphane-equilibria Between Cyclophosphanes (PR)n at Elevated-Temperatures. Z. Naturforsch., B: Anorg. Chem., Org. Chem. 1984, 39, 438-444.

23. (a) Mathey, F., The chemistry of phospha-and polyphosphacyclopentadienide anions. Coord. Chem. Rev. 1994, 137, 1-52; (b) Mathey, F., Recent advances in the chemistry of phospholide and polyphospholide ions. J. Organomet. Chem. 1994, 475, 25-30; (c) Mathey, F., The organic chemistry of phospholes. Chem. Rev. 1988, 88, 429-453.

$24 . \quad$ (a) Duffy, M. P.; Bouit, P. A.; Hissler, M., Applications of Phosphorus-Based Materials in Optoelectronics. John Wiley \& Sons Ltd.: Hoboken, Chichester: 2018; (b) Duffy, M. P.; Delaunay, W.; Bouit, P.-A.; Hissler, M., $\pi$-Conjugated phospholes and their incorporation into devices: components with a great deal of potential. Chem. Soc. Rev. 2016, 45, 52965310; (c) Baumgartner, T., Insights on the design and electron-acceptor properties of conjugated organophosphorus materials. Acc. Chem. Res. 2014, 47, 1613-1622; (d) Romero-Nieto, C.; Baumgartner, T., Dithieno [3, 2-b: 2' , 3' -d] phospholes: A Look Back at the First Decade. Synlett 2013, 24, 920-937; (e) Ren, Y.; Baumgartner, T., Combining form with functionthe dawn of phosphole-based functional materials. Dalton Trans. 2012, 41, 7792-7800; (f) Román, E.; Leiva, A. M.; Casasempere, M. A.; Charrier, C.; Mathey, F.; Garland, M. T.; Le Marouille, J.-Y., Nouvell préparation, propriétés electrochimiques et etude structurale des phosphaferrocenes $\eta 5$ C5Me5Fe- 5 -PC4 (R4). J. Organomet. Chem. 1986, 309, 323-332; (g) Thomson, C.; Kilcast, D., Novel Radicals from the Reaction of Phospholes with Potassium. Angew. Chem. Int. Ed. Engl. 1970, 9, 310-311; (h) Krauss, I. J.; Wang, C. C.-Y.; Leighton, J. L., Highly regioselective and diastereoselective directed hydroformylation of allylic ethers: a new approach to propionate aldol synthesis. J. Am. Chem. Soc. 2001, 123, 11514-11515; (i) Asok, N.; Gaffen, J. R.; Pradhan, E.; Zeng, T.; Baumgartner, T., Structure-reactivity studies on hypervalent squarepyramidal dithieno [3, 2-b: 2' , 3' -d] phospholes. Dalton Trans. 2021, 50, 2243-2252; (j) Gaffen, J. R.; Bentley, J. N.; Torres, L. C.; Chu, C.; Baumgartner, T.; Caputo, C. B., A simple and effective method of determining Lewis acidity by using fluorescence. Chem 2019, 5, 1567-1583. 25. (a) Xu, Y.; Wang, Z.; Gan, Z.; Xi, Q.; Duan, Z.; Mathey, F., Versatile synthesis of phospholides from open-chain precursors. Application to annelated pyrrole-and silole-phosphole rings. Org. Lett. 2015, 17, 1732-1734; (b) Westerhausen, M.; Digeser, M. H.; Nöth, H.; Ponikwar, W.; Seifert, T.; Polborn, K., 2, 5-Diphenyl-3, 4-bis (trimethylsilyl)-1-phosphacyclopentadienide as a Ligand at Calcium, Strontium, and Tin (II). Inorg. Chem. 1999, 38, 3207-3214; (c) Gudat, D. Bajorat, V.; Häp, S.; Nieger, M.; Schröder, G., Reduction of Bis (phosphonio) isophosphindolides to Phosphane - Functionalized Benzo [c] phospholides. Eur. J. Inorg. Chem. 1999, 1999, 1169-1174; (d) Holand, S.; Jeanjean, M.; Mathey, F., A Straightforward Access to a - Functional Phospholide Ions. Angew. Chem. Int. Ed. Engl. 1997, 36, 98-100; (e) Niecke, E.; Nieger, M.; Wenderoth, P., Phosphindolyl Anions by Elimination from 1 - Phosphoallyllithium Complexes - $\eta 5$ and $\eta 3$ Coordination of a Phospholyl Fragment. Angew. Chem. Int. Ed. Engl. 1994, 33, 353-354; (f) Braye, E.; Caplier, I.; Saussez, R., Alkali aza-, phospha-and arsacyclopentadienides and their chemical properties. Tetrahedron 1971, 27, 5523-5537.

26. (a) Luo, G.; Du, S.; Wang, P.; Liu, F.; Zhang, W.-X.; Luo, Y., Fragmentation Mechanism of White Phosphorus: A Theoretical Insight into Multiple Cleavage/Formation of $\mathrm{P}-\mathrm{P}$ and $\mathrm{P}-\mathrm{C}$ Bonds. Chem. Eur. J. 2020, 26, 13282-13287; (b) Hu, J.; Chai, Z.; Liu, W.; Huang, Z.; Wei, J.; Zhang, W.-X., Phosphafluorenyl lithiums: direct synthesis from white phosphorus, structure and diversified synthons. Sci. China Chem. 2022, DOI: $10.1007 / \mathrm{s} 11426-021-1139-0$. 


\section{SYNOPSIS TOC}

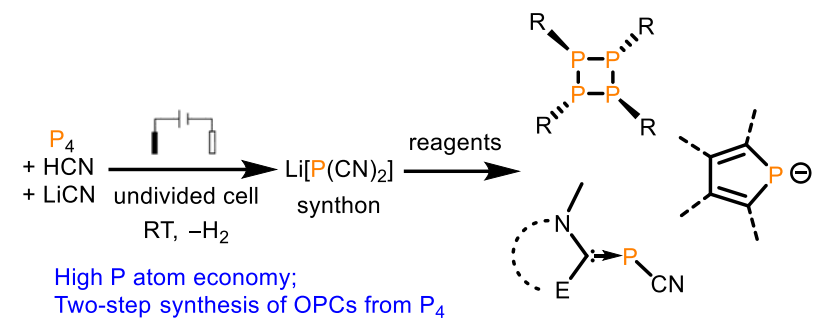

